\title{
1. Ethylene epoxidation in microwave heated structured reactors
}

\author{
2. 1 Adrián Ramírez ${ }^{a}$, José L. Hueso ${ }^{\mathrm{a}, \mathrm{b}, *}$, Reyes Mallada ${ }^{\mathrm{a}, \mathrm{b}}$, Jesús Santamaría ${ }^{\mathrm{a}, \mathrm{b}, *}$ \\ 3 Q2 a Institute of Nanoscience of Aragon and Department of Chemical and Environmental Engineering, University of Zaragoza, Campus Río Ebro, Edificio I+D, \\ C/Mariano Esquillor s/n, 50018 Zaragoza, Spain \\ ${ }^{\mathrm{b}}$ Networking Research Center on Bioengineering, Biomaterials and Nanomedicine (CIBER-BBN), 28029 Madrid, Spain
}

\section{A R T I C L E I N F O}

\section{Article history:}

Received 1 December 2015

Accepted 4 January 2016

Available online xxx

\section{Keywords:}

Microwave heating

Microwave susceptors

Ethylene epoxidation

Monoliths

\begin{abstract}
A B S T R A C T
In the present work we show the microwave-induced heating of monolithic reactors containing a thinlayered catalyst that exhibits a strong and selective heating susceptibility under microwave irradiation. The combination of microwave radiation and structured reactors has been successfully applied for the intensification of the selective oxidation of ethylene to ethylene oxide (epoxidation) while operating at lower power consumptions and with higher energy efficiencies than in conventional heating conditions. The microwave radiation selectively heats the catalyst and the monolith walls while maintaining a relatively colder gas stream thereby creating a gas/solid temperature gradient of up to $\sim 70{ }^{\circ} \mathrm{C}$ at a reaction temperature of $225^{\circ} \mathrm{C}$. Moreover, the influence of different parameters such as the distribution of the catalyst onto the structured monoliths or the temperature measurement techniques employed to determine the heating profiles (Optic Fibers and/or IR thermography) have been also thoroughly evaluated to justify the obtained catalytic results.
\end{abstract}

(C) 2016 Published by Elsevier B.V.

\section{Introduction}

Process Intensification (PI) is currently considered as one of the most important progress areas for modern chemical engineering. PI involves the development of novel reactor designs and concepts to promote safe, cost-effective and energy-efficient sustainable processes $[1,2]$. In this regard, the combination of microwave heating and the use of structured reactors represent a promising concept in the framework of Process Intensification. Monolithic supports provide an arrangement of straight narrow channels of well-defined sizes and shapes that can be properly coated with a thin layer of a catalytic active phase. This configuration minimizes pressure drops and mass-transfer limitations of conventional packed-bed systems [3-7]. Moreover, since the cordierite base material is essentially MW-transparent, the selective heating of the catalyst by the electromagnetic wave in gas/solid systems has additional advantages in terms of energy savings due to the specific heating of the microwave "susceptor" catalyst and the surrounding fluid. This process reduces the possibility of secondary reactions and facilitates

Q3 * Corresponding authors at: Institute of Nanoscience of Aragon and Department of Chemical and Environmental Engineering, University of Zaragoza, Campus Río Ebro, Edificio I+D, C/Mariano Esquillor s/n, 50018 Zaragoza, Spain.

E-mail addresses: jlhueso@unizar.es (J.L. Hueso), Jesus.Santamaria@unizar.es (J. Santamaría). desorption of targeted end-products into a comparatively cooler gas stream.

The use of MW heating has been largely explored to develop novel synthetic materials and organic routes of interest at significantly shorter reaction times $[8,9]$. Likewise, MW heating has been also expected to improve the catalytic results obtained by conventional heating due to the intrinsic advantages of microwave irradiation: volumetric and selective heating with energy saving, improve conversion and product yields, reduce reaction times and rapid on-and-off action. Nevertheless, MW heating has not fully explote its potential in heterogeneous gas-phase catalysis yet. One of the main reasons can be attributed to the lack of full understanding about the real effects of microwaves when interacting with the gas/solid interface of catalysts under a real reaction ambient. Other important issue deals with the number of publications available in the literature that contain contradictory results to justify the MWinduced real influence in the catalytic results. Some investigators report enhancement of the reaction selectivities or low operational temperatures due to the MW-heating [10-15] while many others do not observe such enhancements [16-20]. Recent reviews of the current state of the art $[11,21]$ in this field have drawn an important conclusion: a non-accurate measurement of the reaction temperatures under MW irradiation can lead to a misleading interpretation of the catalytic final results.

In this work, we have evaluated the intensification of the ethylene epoxidation to generate ethylene oxide (hereafter EO), a 


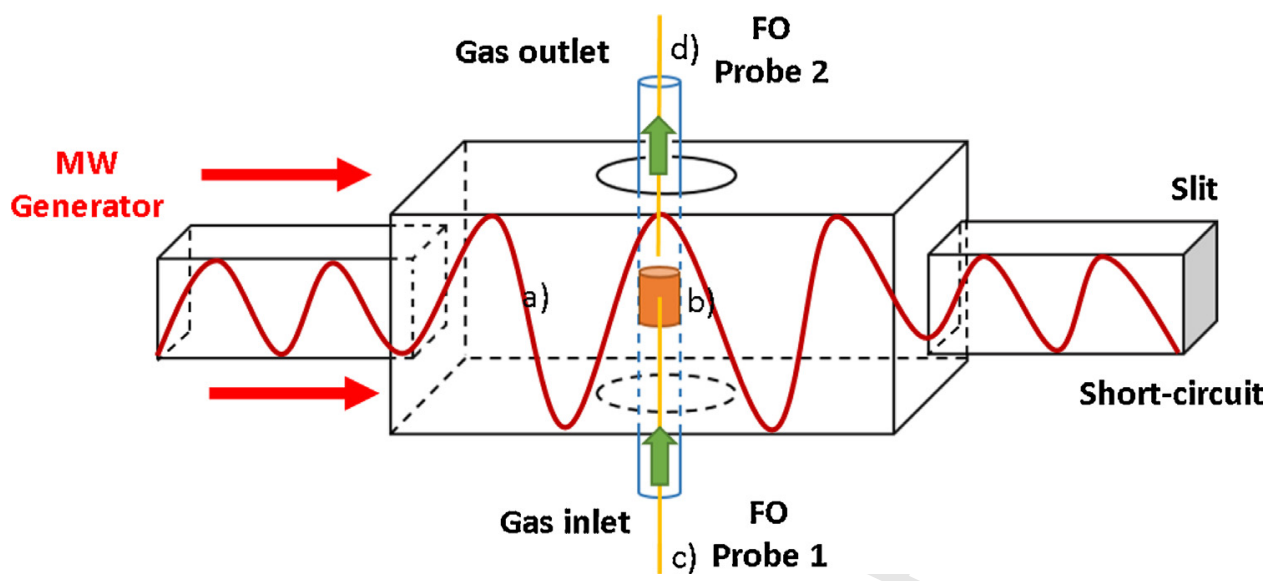

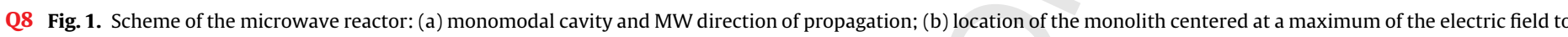

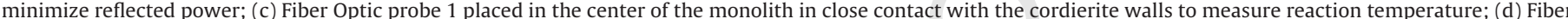

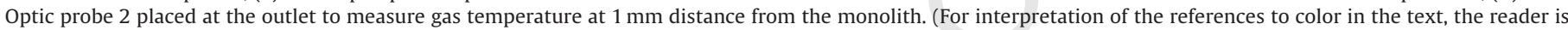
referred to the web version of this article.)

chemical intermediate of paramount importance in the chemical industry that shows room for the improvement of the synthesis conditions in terms of efficiency, costs, conversion and selectivity $[22,23]$. A novel alternative based on the sinergetic advantages of combining MW dielectric heating and structured cordierite monoliths is proposed. The structured reactor contains a thin layer of catalyst [24] that simultaneously provides a selective heating upon MW irradiation and a remarkable activity for the selective conversion of ethylene to EO.

\section{Experimental}

\subsection{Preparation of the catalytic monoliths}

The structured reactor was prepared using cordierite monoliths (purchased from $\mathrm{GmbH}$ with $400 \mathrm{cpsi}$ ). The dimensions of the monoliths were $12 \mathrm{~mm}$ of diameter and $15 \mathrm{~mm}$ of side length. The epoxidation catalyst was prepared according to a recently established methodology under patent licensing [24]. The catalyst loading was carried out after the immersion of the monoliths in the presence of an ethanolic suspension $(1.5 \mathrm{~g}$ of catalyst in $50 \mathrm{~mL}$ ) inside an ultrasonic bath for 30 min followed by calcination $(2 \mathrm{~h}$ ) at $250^{\circ} \mathrm{C}$. This process was repeated three times until the targeted catalyst loading was achieved (10\% weight). Likewise, the ultrasound assisted deposition of the catalyst layer was carried out either with the monolith standing still in horizontal position within the sonication vessel or vertically suspended with the aid of tweezers. The latter approach rendered a more homogeneous dispersion of the catalyst layer.

\subsection{Microwave-related equipment and characterization techniques}

The microwave cavity employed was a $(5,1,0)$ monomodal cavity wave guide with a frequency of $2.45 \mathrm{GHz}$ provided by Sairem Iberica. Temperature distributions were registered by IRthermography and using Fiber Optic probes. The thermographic camera is a NEC InfRec R300 which operates over 8-14 $\mu \mathrm{m}$ and allows temperature measurement between $-40^{\circ} \mathrm{C}$ and $-500^{\circ} \mathrm{C}$. The emissivity of each material needs to be calibrated and it can be defined as the radiation emitted by a certain body in comparison with the radiation emitted by a black body. The hotter an object is, the higher fraction of infrared radiation emitted. Emissivity values range from 0 (mirror) to 1.0 (black body).
The Fiber Optic is a Neoptix Fiber Optic sensors which is based on a well-known semiconductor phenomenon: the band-gap variation in the absorption spectrum of gallium arsenide (GaAs) with temperature. The Fiber Optic is connected with a multichannel Fiber Optic signal conditioner Neoptix ${ }^{\mathrm{TM}}$ Reflex $^{\mathrm{TM}}$. The temperature measured by the Fiber Optic probe was recorded by Neoptix NeoLink ${ }^{\mathrm{TM}}$ software. The temperature range is between -270 to $+250^{\circ} \mathrm{C}$. The morphology of the catalysts was characterized by scanning electron microscopy, SEM (FEI-Inspect S50) at the Laboratory of Advanced Microscopies, -LMA, University of Zaragoza. The dielectric properties of the materials were measured at $2.45 \mathrm{GHz}$ with the network analyzer (Agilent E5061B 5Hz-3 GHz, using the 8570 E dielectric probe kit). The probe was inserted into a Teflon cup $(20 \mathrm{~mm}$ high and $10 \mathrm{~mm}$ diameter) covered with a lid and the powders were compacted manually, using always the same amount of powder inside the container. Dielectric constant and loss factor data were reported as the average of 20 measurements.

\subsection{Microwave dielectric heating and catalytic tests}

The experimental set-up is described in Fig. 1. Microwaveinduced heating was supplied by a mono-modal microwave applicator operating at $2.45 \mathrm{GHz}$. The monolith (in orange) is place inside a quartz tube ( $12 \mathrm{~mm}$ inner diameter) located in the middle of the microwave cavity, were the electric field is maximized. The temperature was measured with the aid of two Fiber Optics placed inside the central channel of the monolith (labelled as probe 1 ), and at the outlet gas/solid interphase at $1 \mathrm{~mm}$ of the monolith (labelled as probe 2), respectively. Temperature and power thresholds were limited to $225^{\circ} \mathrm{C}$ and $40 \mathrm{~W}$, respectively. The reaction temperature was increased from 135 to $225^{\circ} \mathrm{C}$ in steps of $25^{\circ} \mathrm{C}$, varying the microwave power and measuring the composition of the outflow for each temperature. The inlet flow was fed upstream with a composition of $6 \%$ of ethylene, $12 \%$ oxygen and $82 \%$ helium, and the flow rate was set to obtain a WHSV of $0.2 \mathrm{~mL} / \mathrm{min} \mathrm{mg}_{\text {cat }}$. The outlet composition was analyzed by a gas chromatograph (Agilent 490 Micro GC) equipped with thermal conductivity detectors and two gas separation columns, CP17970 and CP17971. For conventional heating, the same quartz tube was placed inside an electrical oven. Temperature profiles were measured with a thermocouple located either located in the center of the monolith or at $1 \mathrm{~mm}$ of distance in the gas outlet section and connected to a PID controlled electrical furnace to maintain the desired temperature. It should be noted that no traces of acetaldehyde could be detected in any reaction conditions. 

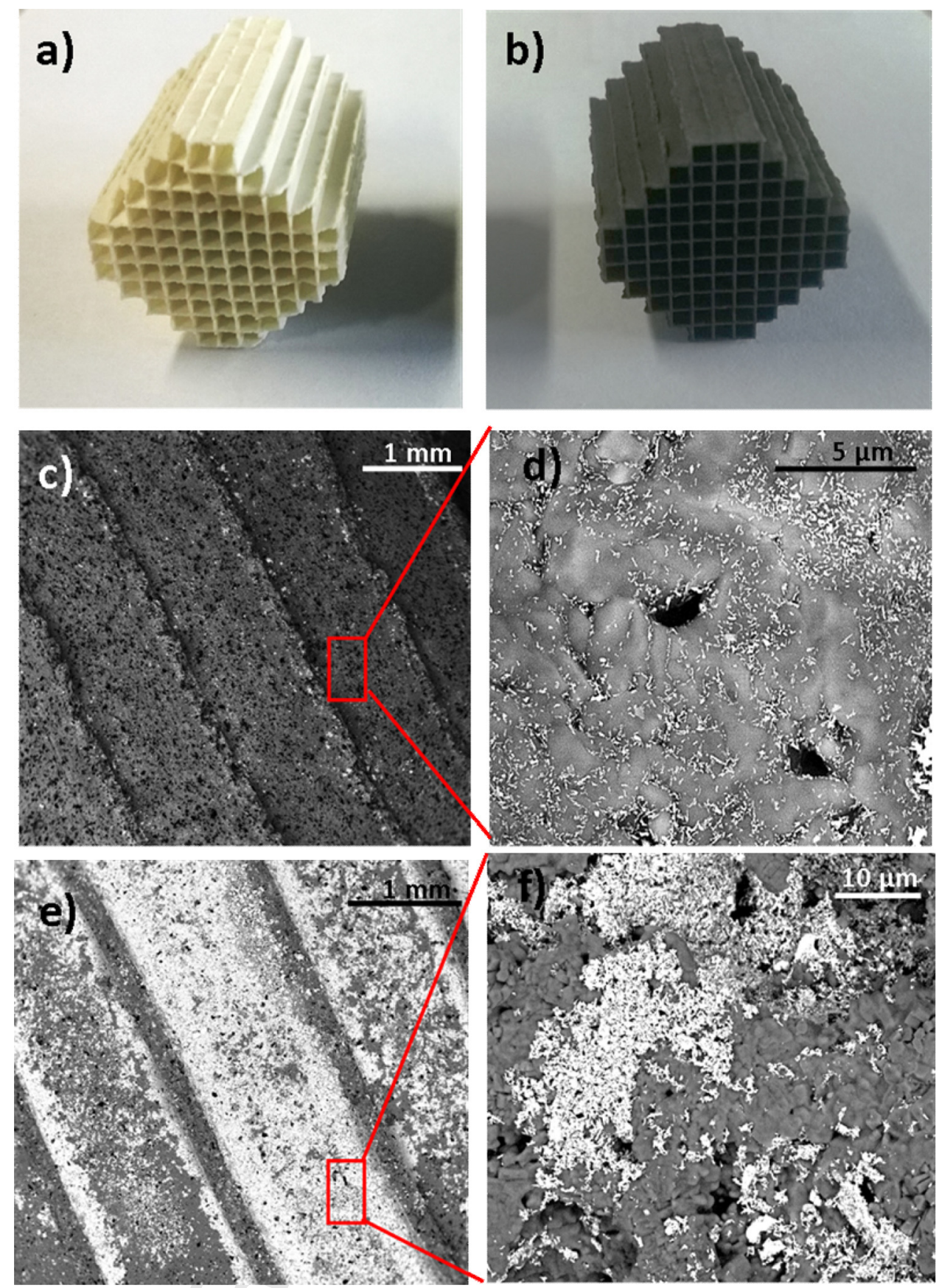

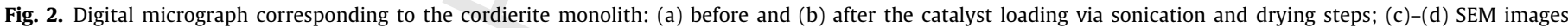

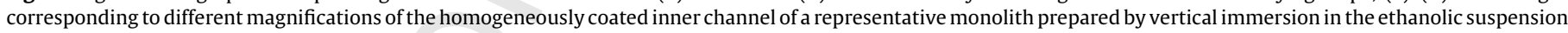

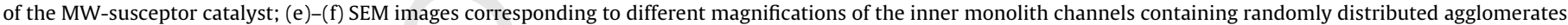
and inhomogeneities after placing the monolith in horizontal position during the immersion-deposition-sonication sequence.

\section{Results and discussion}

\subsection{Preparation of the monoliths}

Fig. 2 shows the typical aspect of the monoliths before and after the catalyst loading (Fig. $2 \mathrm{a}$ and $\mathrm{b}$ ). In all cases, the required number of loading repetitions was set to three and a very similar and reproducible weight increment was determined for all the prepared monoliths from $\sim 5.6 \%$ to $\sim 8.5 \%$ and finally $\sim 10 \%$ wt in the third loading repetition. SEM images of the middle sections of the monoliths helped to differentiate the influence of the initial position of the monolith during the immersion-sonication-deposition sequence. The monoliths placed vertically during the catalyst loading step showed a really homogeneous distribution of the catalyst and a very close contact with the monolithic walls (Fig. 2c and d). In contrast, placing the monolith in horizontal position favored the formation of a major fraction of agglomerates (Fig. 2e and $f$ ).

\subsection{Measurement of dielectric properties and temperature in the loaded monoliths}

\subsubsection{Determination of dielectric properties}

Dielectric properties that predict the capability of a particular material to be heated in the presence of a microwave field were

Please cite this article in press as: A. Ramírez, et al., Ethylene epoxidation in microwave heated structured reactors, Catal. Today (2016), http://dx.doi.org/10.1016/j.cattod.2016.01.007 
Table 1

Dielectric properties of the evaluated materials at $25^{\circ} \mathrm{C}$ and $2.45 \mathrm{GHz}$.

\begin{tabular}{lcll}
\hline & $\varepsilon^{\prime}$ (Dielectric constant) & $\varepsilon^{\prime \prime}$ (Dielectric loss) & $\delta$ (Loss tangent) \\
\hline Bare catalyst & 110.5 & 113.8 & 1.029 \\
Loaded monolith & 2.2 & 0.04 & 0.020 \\
Bare monolith & 1.5 & 0.007 & 0.004 \\
\hline
\end{tabular}

measured with the aid of an Agilent E5061B network analyzer. Dielectric constant $\left(\varepsilon^{\prime}\right)$, dielectric loss $\left(\varepsilon^{\prime \prime}\right)$ and the loss tangent (i), (the latter represented as the ratio between $\varepsilon^{\prime \prime}$ and $\varepsilon^{\prime}$ ), were experimentally measured for the cordierite monolith, the bare epoxidation catalyst and the ground loaded monolith, respectively at $25^{\circ} \mathrm{C}$ and working at $2.45 \mathrm{GHz}$. The magnitudes of these parameters have been summarized in Table 1 (vide infra). From these preliminary measurements, it was concluded that the catalyst possessed the highest loss tangent value $(\delta)$, the magnitude that better anticipates an optimum MW coupling and higher heating capacity [21]. Likewise, it was also observed how the catalyst loading enhanced the $\delta$ value of the bare cordierite (5-fold increment) that was almost MW transparent (Table 1).

\subsubsection{Infrared temperature measurements}

Additionally and prior to the catalytic activity tests, multiple temperature measurements under MW radiation were systematically carried out in order to evaluate the homogeneity of the monolith and the accuracy of two different measurement techniques selected as the most accurate and reproducible from the literature [21]. A first approach to determine the temperature distribution within the loaded monolith was carried out with the aid an infrared (IR) thermographic camera. First of all, the emissivity of the loaded monolith was calibrated by infrared (IR) thermography, after comparing the infrared emission of a black body of known emissivity of 1 and a compressed pellet containing the ground monolith with $10 \%$ wt catalyst and heated up to $100^{\circ} \mathrm{C}$ in a hot plate. The emissivity of the monolith pellet was readjusted and set to 0.8 .

Fig. 3 shows a series of thermographic images recorded with the IR-camera depicting the sequencial heating evolution of the monolith (top-view) under MW irradiation at $15 \mathrm{~W}$, at different operation times in air. The mapping of temperatures showed a preferential heating in the monolith walls whereby the catalyst had been homogeneously deposited while the inner volume of the channels remained colder. Regarding the heating rate, more than $100^{\circ} \mathrm{C}$ were achieved after one single minute of MW irradiation. It is also worth noting that the observed heating was quite homogeneous and reproducible from sample to sample, not only on the edges of the monolith (top views in Fig. 3a and c) but also along the side walls of the whole monolith (side-view in Fig. 3d). Therefore, these temperature distributions discarded the presence of temperature in homogeneities previously attributed to other samples exposed to MW heating and attributed to the lack of uniformity of the electric field $[21,25]$.

\subsubsection{Temperature measurements using Fiber Optic probes}

In addition to the use of an IR camera, a second temperature measurement technique based on the use of Fiber Optics (FO) was further implemented. Durka et al. $[21,25,26]$ have previously claimed that IR thermometry suffered from certain intrinsic drawbacks such as the close dependence on the emissivity of each specifically measured material and more importantly, it is considered an accurate technique only for surface measurements. Therefore, the use of FO probes has been reported as the ideal alternative to measure reaction temperatures under MW heating conditions, regardless of the material composition and with no need of additional recalibrations [25]. As previously described in the schematic setup of Fig. 1, one FO probe was placed inside the monolith central channel with the motivation of monitoring the temperature during the epoxidation tests (Fig. 4a). In order to test the homogeneous heating of the monolith in the presence of the FO probe, an additional mapping of temperatures was recorded with the IR camera under MW heating conditions. In this case, He was selected as carrier gas during the heating experiment and the IRcamera was placed upstream at the outlet of the opened quartz tube reactor to avoid any infrared radiation absorption from the quartzmade reactor walls. The thermal image shown in Fig. 4b further corroborated the expected stacking of the flow in the central channel where the FO was placed in close contact with the cordierite walls. Therefore, it was possible to assume that a homogeneous heating was being achieved under MW reaction conditions in the whole monolithic reactor and that real tests to measure the epoxidation activity could be subsequently carried out. It is also worth to note that the temperature differences observed in Fig. 4b must be only associated to the different emissivities of the FO probe and the cordierite monolith, thereby meaning that the whole system remains at a constant and identical temperature.

\subsection{Ethylene epoxidation tests}

Fig. 5 shows the ethylene conversion during the epoxidation reaction at increasing gas temperature values determined with the aid of FO probe 2 (see Fig. 1 and Section 2) under MW heating conditions or alternatively with a thermocouple placed at the same distance ( $1 \mathrm{~mm}$ from the monolith surface at the gas outlet) under conventional (electrically induced) heating. Interestingly, it can be observed that for a given conversion, the gas temperature in the case of microwave heating is always lower, being as low as $\sim 150^{\circ} \mathrm{C}$ for a conversion of $9 \%$ and meaning an equivalent gas temperature of $225^{\circ} \mathrm{C}$ and $\sim 70^{\circ} \mathrm{C}$ of gradient in comparison with the conventional heating conditions. Although this temperature gradient concept has been previously investigated, it has been traditionally attributed to non-uniformities in the electric field or to the formation of localized hot spots [27,28]. Nevertheless, Santamariaís group has recently started to investigate the use of monolithic systems where exists a clear separation between the gas and the solid phase [29]. An analogs temperature gradient was measured in the presence of a monolithic reactor coated with perovskite during the total oxidation of n-hexane under MW irradiation. This gradient was attributed to the selective heating of the catalyst and reflects a different heating dynamics. In contrast to conventional heating (where the catalyst is heated by conduction through the reactor and convection from the gas phase and the gas-solid temperature gradient is minimal), in the MW-induced heating mechanism the locally MW susceptor rapidly transfer the heat to the MWtransparent cordierite and the colder gas stream. Therefore a lower amount of energy was required to heat the gas stream and a more efficient system was obtained.

Fig. 6 shows the selectivity and conversion achieved in the epoxidation of ethylene at different reaction temperatures acquired with the aid of the FO probe 1 placed in the central monolith channel (under MW irradiation) or alternatively using a thermocouple placed in the same position under conventional heating. Almost identical conversion and selectivities were obtained for a the monolith with the homogeneous distribution of catalyst, regardless of the heating mechanism (Fig. 6a and b) and accounting for the good thermal homogeneity along the channels of the monoliths. Interestingly, the selectivity to ethylene epoxide and the conversion achieved outperform other analogous systems based on silver or silver-copper alloys [30-32]. Furthermore, the operation with minimal power consumption (less than $40 \mathrm{~W}$ ) and the milder heating of the gas stream represents a great advantage for saving reaction times and energy costs in the gas cooling post-treatment typically 

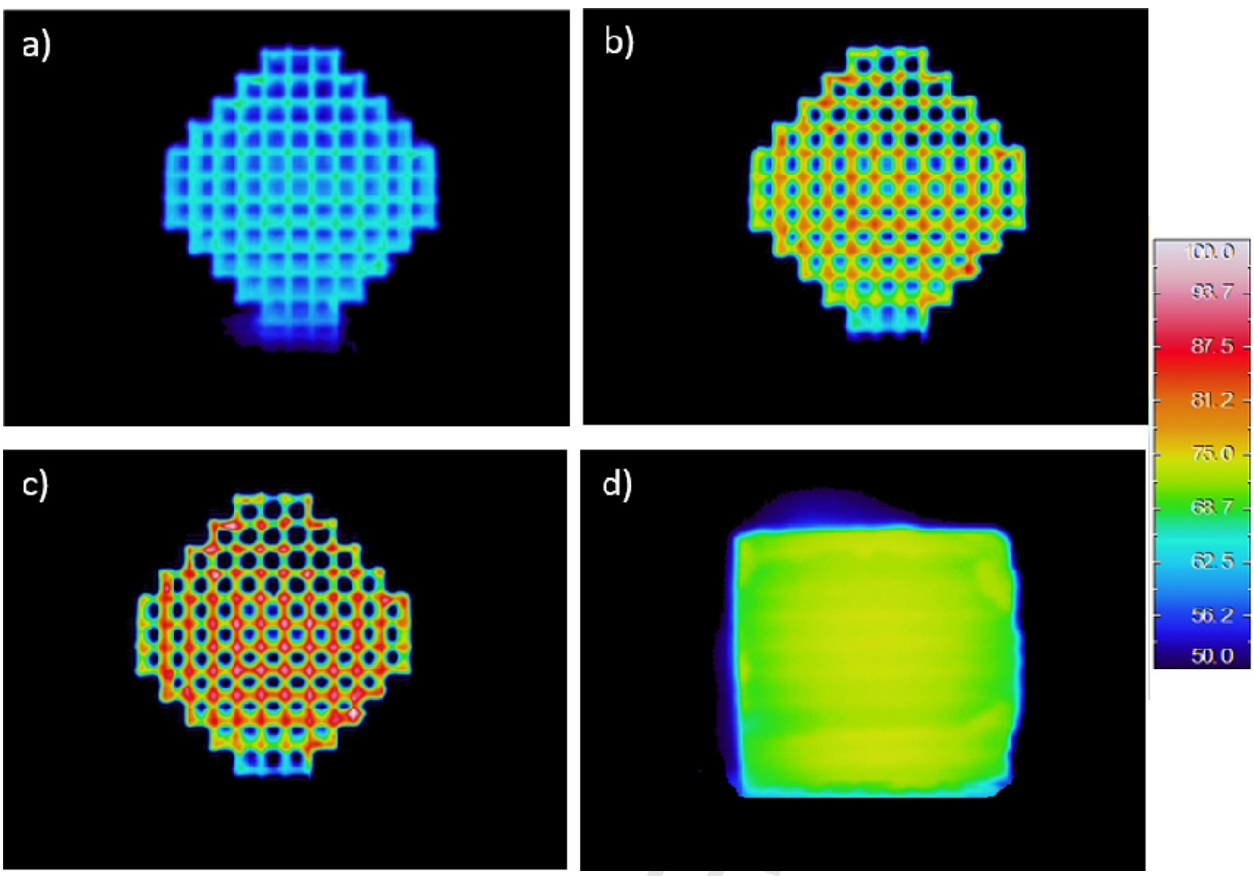

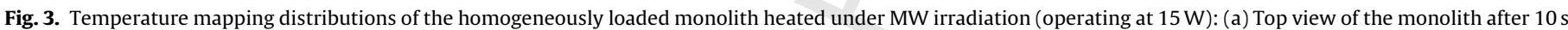

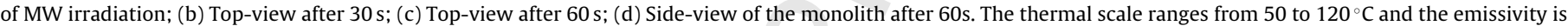
adjusted to 0.8 .
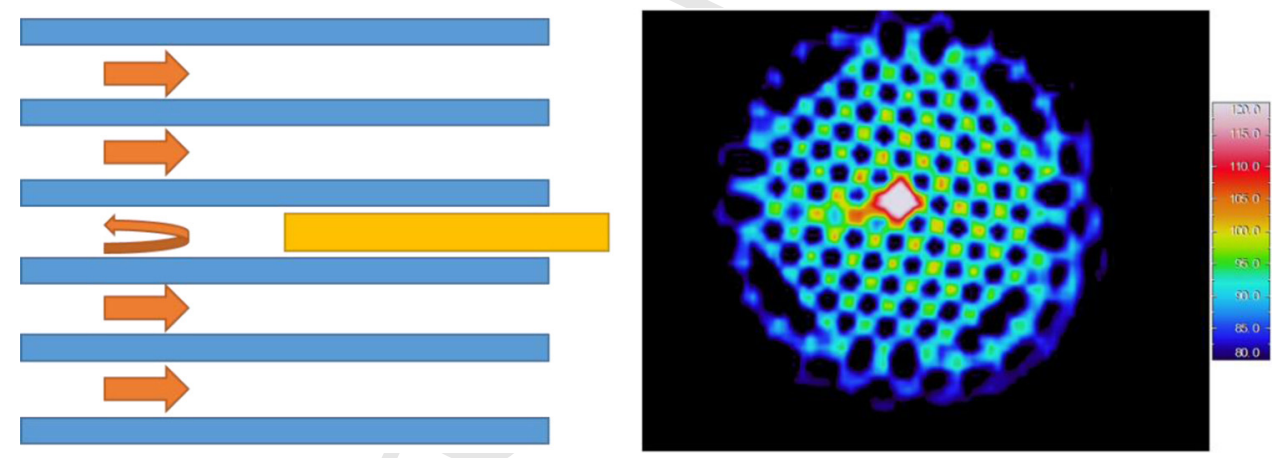

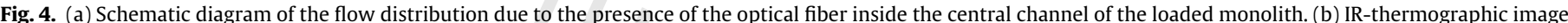

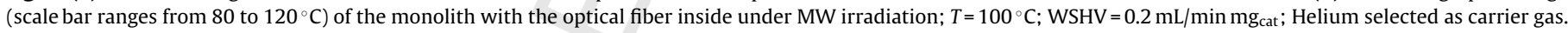

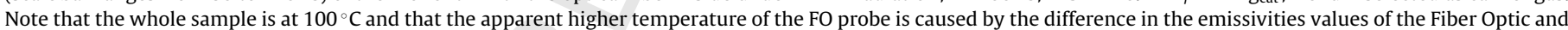
the cordierite, respectively.

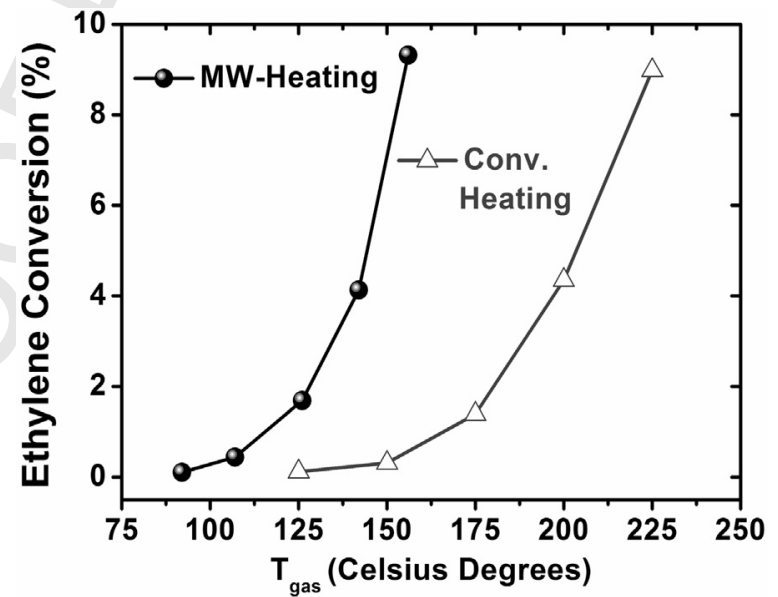

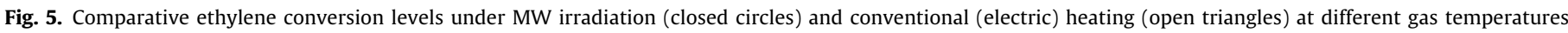

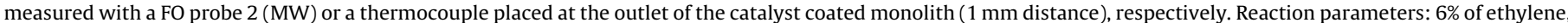
$12 \%$ oxygen and $82 \%$ helium, and the flow rate was set to obtain a WHSV of $0.2 \mathrm{~mL} / \mathrm{min} \mathrm{mg}$ cat

Please cite this article in press as: A. Ramírez, et al., Ethylene epoxidation in microwave heated structured reactors, Catal. Today (2016), http://dx.doi.org/10.1016/j.cattod.2016.01.007 

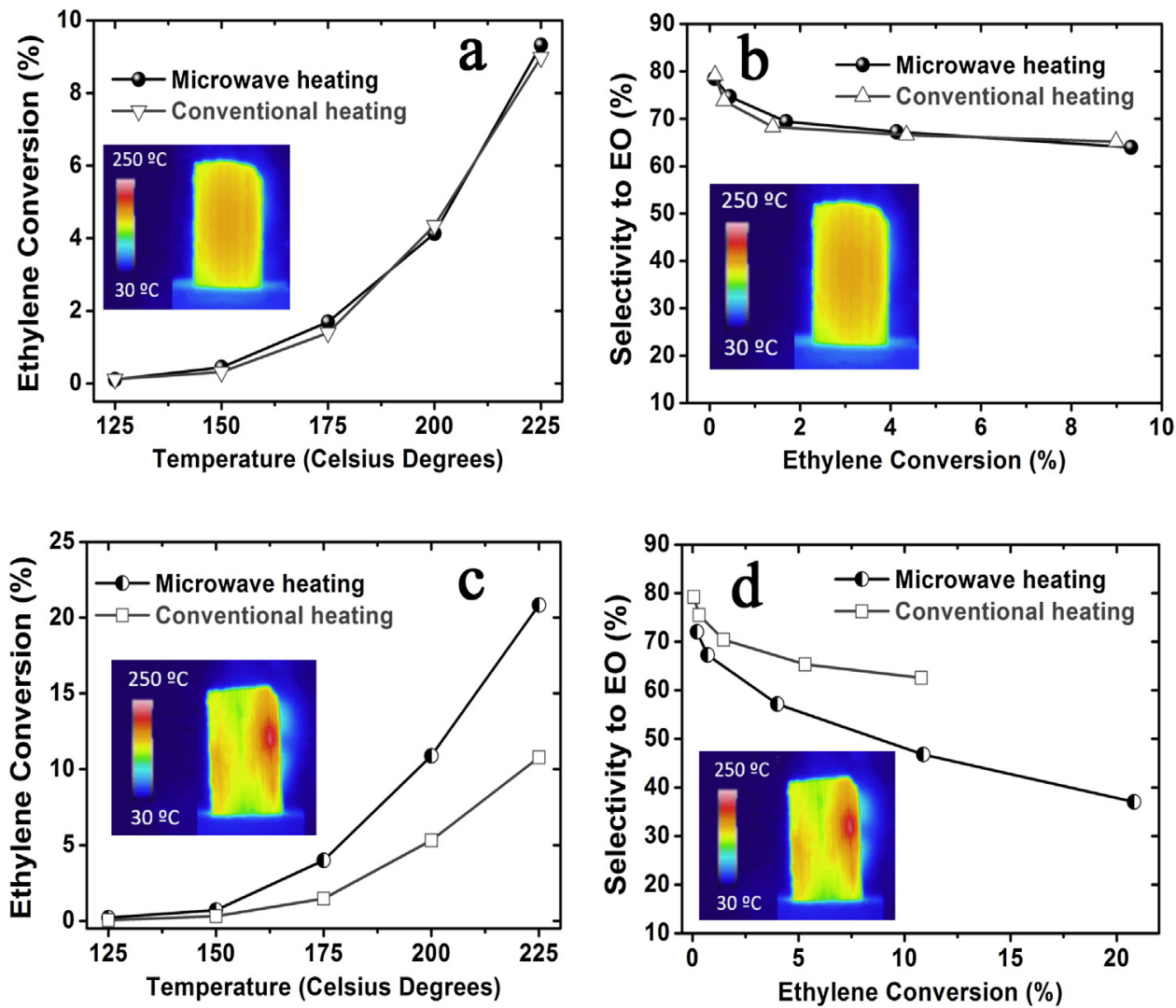

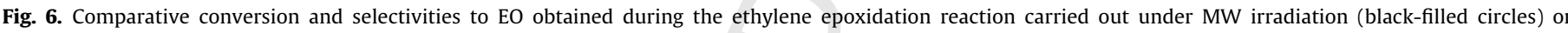

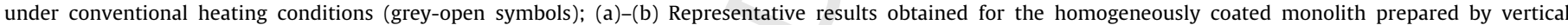

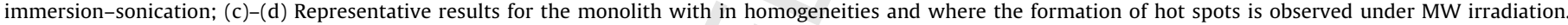

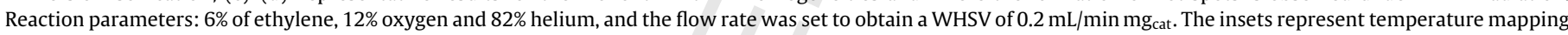
distributions of the monoliths acquired by IR-thermometry after a longitudinal cut along the monolith to account for the formation of hot spots.

employed for the separation and purification of the epoxide fraction $[4,33]$.

On the contrary, in the case of the less homogeneously coated monolith (Fig. 2e and f), a significant increment on the ethylene conversion was detected at the expense of a lower selectivity to EO (Fig. $6 \mathrm{c}$ and d). These differences were attributed to the formation of localized hot spots under MW irradiation in certain areas of the monolith where major agglomerations of catalyst had been identified by SEM (Fig. 2e and f) and with the aid of IR-measurements carried out with the longitudinally cut monoliths (see insets in Fig. $6 \mathrm{c}$ and $\mathrm{d}$ accounting for the presence of hotter spots at considerably higher temperature of reaction). This accumulation of catalyst has been considered as the main cause of the lower selective to ethylene oxide (Fig. 6d). Thus, the catalyst deposition step seems to be critical and the immersion of the monolith looks as the most promising alternative for a homogeneous deposition. If the catalyst is accumulated in some of the inner channels will lead to the formation of hot spots under microwave heating since there is more material in the same area susceptible to absorb microwave energy and favor the non-selective side reaction of total combustion of ethylene toward carbon dioxide via an acetaldehyde intermediate formation $[4,30,34]$.

\section{Conclusions}

It has been demonstrated that the formation of hot spots, caused by the local agglomeration of catalyst in certain channels of the monoliths, leads to enhanced conversion values at the expense of lower selectivities. These catalytic results contrast with welldispersed monoliths that show no differences in the activity in comparison with conventional heating at similar reaction temperatures. The main advantage of using MW heating finally strives on the higher energy efficiency achieved during the selective heating of the MW susceptor. The catalyst is able to rapidly transfer the heat to the MW-transparent cordierite support while maintaining the gas stream at lower temperature in contrast to conventional heating mechanisms that work with conduction-convection mechanisms with minimal gas-solid temperature gradients. This particular aspect represents an important advantages for potential industrial applications since the post-treatment purification of gas streams for recovery and purification of EO can be avoided. The combined use of Fiber Optics probes and IR thermography has been also addressed as the most suitable and accurate methodology to throughouly acquire a correct measurement of the temperature within the monolithic reactor under MW irradiation conditions.

\section{Acknowledgments}

Financial support from the European Research Council Q6 330 Advanced Grant (HECTOR-267626) and the Regional Government of Aragon (DGA) is gratefully acknowledged. We also thank $\mathrm{Mr}$. Hakan Nigar for his help in the measurement of dielectric properties.

\section{References}

[1] G.D. Stefanidis, A.N. Munoz, G.S.J. Sturm, A. Stankiewicz, Rev. Chem. Eng. 30 (2014) 233-259.

[2] G.S.J. Sturm, M.D. Verweij, A.I. Stankiewicz, G.D. Stefanidis, Chem. Eng. J. 243 (2014) 147-158

[3] J.L. Williams, Catal. Today 69 (2001) 3-9. 
G Model

CATTOD 9968 1-7

A. Ramírez et al. / Catalysis Today $x x x$ (2016) $x x x-x x x$

7

341 [4] G. Groppi, E. Tronconi, Catal. Today 69 (2001) 63-73.

[5] G. Groppi, E. Tronconi, Catal. Today 105 (2005) 297-304.

[6] T. Boger, A.K. Heibel, Chem. Eng. Sci. 60 (2005) 1823-1835.

[7] T. Boger, A.K. Heibel, C.M. Sorensen, Ind. Eng. Chem. Res. 43 (2004) 4602-4611.

[8] R.S. Varma, Green Chem. 1 (1999) 43-55.

[9] P. Lidström, J. Tierney, B. Wathey, J. Westman, (2001) 9225-9283.

[10] G. Bond, R.B. Moyes, D.A. Whan, Catal. Today 17 (1993) 427-437.

[11] T. Krech, R. Krippendorf, B. Jäger, M. Präger, P. Scholz, B. Ondruschka, Chem. Eng. Process. 71 (2013) 31-36.

[12] M.S. Ioffe, S.D. Pollington, J.K.S. Wan, J. Catal. 151 (1995) 349-355.

[13] X.-j. Bi, P.-j. Hong, X.-g. Xie, S.-s. Dai, React. Kinet. Catal. Lett. 66 (1999) 381-386.

[14] J. Beckers, L.M. van der Zande, G. Rothenberg, ChemPhysChem 7 (2006) 747-755.

[15] X. Zhang, D.O. Hayward, C. Lee, D.M.P. Mingos, Appl. Catal. B: Environ. 33 (2001) 137-148.

[16] C. Marún, L.D. Conde, S.L. Suib, J. Phys. Chem. A 103 (1999) 4332-4340.

[17] I. Silverwood, G. McDougall, G. Whittaker, J. Mol. Catal. A: Chem. 269 (2007) $1-4$.

[18] I.P. Silverwood, G.S. McDougall, A. Gavin Whittaker, Phys. Chem. Chem. Phys. 8 (2006) 5412-5416.

[19] H. Will, P. Scholz, B. Ondruschka, W. Burckhardt, Chem. Eng. Technol. 26 (2003) 1146-1149.
[20] H. Will, P. Scholz, B. Ondruschka, Top. Catal. 29 (2004) 175-182.

[21] T. Durka, T. Van Gerven, A. Stankiewicz, Chem. Eng. Technol. 32 (2009) $1301-1312$

[22] C.H. Bartholomew, R.J. Farrauto, Fundamentals of Industrial Catalytic Processes, John Wiley and Sons, New York, 2006.

[23] S. Rebsdat, D. Mayer, Ethylene Oxide, in: Ullmann's Encyclopedia of Industrial Chemistry, Wiley-VCH, Weinheim, 2004.

[24] A. Ramirez, J.L. Hueso, H. Suarez, R. Mallada, J. Santamaria, Catalyst based on silver and copper oxide for partial oxidation of alkenes, and process of preparation thereof, U.o. Zaragoza-OTRI (Ed.), ES (2015).

[25] T. Durka, G.D. Stefanidis, T. Van Gerven, A. Stankiewicz, Meas. Sci. Technol. 21 (2010).

[26] M. Komorowska-Durka, M.B. Loo, G.S.J. Sturm, M. Radoiu, M. Oudshoorn, T. Van Gerven, A.I. Stankiewicz, G.D. Stefanidis, Chem. Eng. Process. 69 (2013) 83-89.

[27] M. Hájek, Collect. Czech. Chem. Commun. 62 (1997) 347-354.

[28] T. Durka, G.D. Stefanidis, T. Van Gerven, A.I. Stankiewicz, Int. J. Hydrogen Energy 36 (2011) 12843-12852.

[29] J. Gracia, M. Escuin, R. Mallada, N. Navascues, J. Santamaria, Nano Energy (2016) (submitted for publication).

[30] J.T. Jankowiak, M.A. Barteau, J. Catal. 236 (2005) 366-378.

[31] J.C. Dellamorte, J. Lauterbach, M.A. Barteau, Catal. Today 120 (2007) 182-185.

[32] A.P. Fotopoulos, K.S. Triantafyllidis, Catal. Today 127 (2007) 148-156.

[33] M.O. Özbek, R.A. van Santen, Catal. Lett. 143 (2013) 131-141.

[34] J.C. Dellamorte, J. Lauterbach, M.A. Barteau, Top. Catal. 53 (2010) 13-18.

364
365
366
367
368
369
370
371
372
373
374
375
376
377
378
379
380
381
382
383
384
385
386
387
388

Please cite this article in press as: A. Ramírez, et al., Ethylene epoxidation in microwave heated structured reactors, Catal. Today (2016),

http://dx.doi.org/10.1016/j.cattod.2016.01.007 